\title{
Erratum to: Wand and Weber's Decomposition Model in the Context of Business Process Modeling
}

DOI 10.1007/s12599-012-0238-0

\section{The Authors}

\section{Dr. Florian Johannsen $(\varangle)$}

Prof. Dr. Susanne Leist

Department of Management

Information Systems

University of Regensburg

Universitätsstraße 31

93053 Regensburg

Germany

Florian.Johannsen@

wiwi.uni-regensburg.de

Susanne.Leist@

wiwi.uni-regensburg.de

Published online: 2012-10-31

The online version of the original article can be found under doi: 10.1007/s12599-012-0229-1.

(C) Springer Fachmedien Wiesbaden 2012
Bus Inf Syst Eng (2012) 4(5):271-286

DOI 10.1007/s12599-012-0229-1

Unfortunately, in the section State of the Art of issue 5/2012 an error occurred in the paper entitled "Wand and Weber's Decomposition Model in the Context of Business Process Modeling" by Dr. Florian Johannsen and Prof. Dr. Susanne Leist.

Throughout the paper, the third condition of Wand and Weber's Decomposition model must be correctly termed "losslessness", not "freedom of losslessness". 